RESEARCH ARTICLE

\title{
A simple method for determining optimal fishing strategies using the Beverton and Holt yield per recruit model in fish stocks with parameter uncertainties
}

\author{
S. S. K. Haputhantri \\ Marine Biological Resources Division, National Aquatic Resources Research and Development Agency, Crow Island, Colombo 15.
}

\begin{abstract}
Parameter uncertainties of existing fish stock assessment models may lead to incorrect management recommendations on optimal fishing strategies especially in tropical fisheries. Therefore, it is advisable to consider the effect of uncertainties in the population parameters when formulating management recommendations. This paper attempts to evaluate the parameter uncertainties of the Beverton and Holt yield per recruit model to estimate optimal fishing strategies. A $10 \%$ variation on deterministic estimates of population parameters of Amblygaster sirm off the Western coastal waters of Sri Lanka was used to demonstrate the proposed method. Different magnitudes of perturbations of the estimated values of natural mortality, asymptotic weight and growth coefficient were considered and optimal management parameters of the Beverton and Holt yield per recruit model were determined. Multiple regression models were also formulated to describe the relationships between the uncertain input parameters and the optimal management parameters.
\end{abstract}

Key words: Beverton and Holt yield per recruit model, management recommendations, multiple regression, parameter uncertainties.

\section{INTRODUCTION}

A number of models have been developed to assess stock for prediction of optimal fishing strategies, ${ }^{1-3}$ but there have been uncertainties associated with the outcomes from most models. This could either be associated with the process of estimation of population parameters or the basic assumptions made during the model development. This paper focuses on the former problem of the uncertainty in parameter estimation. It is understood that the uncertainties in estimation of population parameters might result in imprecise estimates of optimal fishing strategies and hence, erroneous management recommendations. ${ }^{4}$ This study attempts to evaluate the impact of parameter uncertainties and the sensitivity of input parameters on the output of Beverton and Holt yield per recruit model ${ }^{3}$ for determining optimal fishing strategies.
The Beverton and Holt yield per recruit ( $\mathrm{Y} / \mathrm{R}$ ) model is one of the popular analytical models available for fish stock assessments. ${ }^{5}$ This model can be described in the following form.

$$
\begin{array}{r}
\mathrm{Y} / \mathrm{R}=\mathrm{F} \exp \left(-\mathrm{M}\left(\mathrm{t}_{\mathrm{c}}-\mathrm{t}_{\mathrm{r}}\right)\right) \mathrm{W}_{\infty} \sum_{\mathrm{n}=0}^{3}\left\{\left[\mathrm{u}_{\mathrm{n}} /(\mathrm{F}+\mathrm{M}+\mathrm{nK})\right][\exp \right. \\
\left.\left.\left(-\left(\mathrm{nK}\left(\mathrm{t}_{\mathrm{c}}-\mathrm{t}_{0}\right)\right)\right)\right]\left[1-\exp \left(-(\mathrm{F}+\mathrm{M}+\mathrm{nK})\left(\mathrm{t}_{\mathrm{j}}-\mathrm{t}_{\mathrm{c}}\right)\right)\right]\right\}
\end{array}
$$

where,

$\mathrm{u}_{0}=1 ; \mathrm{u}_{1}=-3 ; \mathrm{u}_{2}=3 ; \mathrm{u}_{3}=-1$

$\mathrm{F}=$ instantaneous rate of fishing mortality

$\mathrm{M}=$ instantaneous rate of natural morality

$\mathrm{t}_{\mathrm{c}} \quad=$ age at first capture

$\mathrm{t}_{\mathrm{r}} \quad=$ age of recruitment

$\mathrm{W}_{\infty}=$ asymptotic weight

$\mathrm{K}=$ Von Bertalanffy growth coefficient

$\mathbf{t}_{\mathrm{n}}=$ theoretical age at zero length

$\mathbf{t}_{1}=$ age of the oldest fish in stock.

Of the eight parameters of the above model, the only controllable variables are $F$ and $t_{c}$ ( $F$ is proportional to fishing effort while $t_{c}$ is a function of gear selectivity). In general, $M, W_{\infty}$ and $K$ are relatively uncertain parameters compared to the age parameters (i.e. $t_{0}, t_{1}, t_{r}$ ), hence the former are considered as the key parameters influencing management recommendations. Therefore, quantifying these uncertainties in the process of assessment of stocks is essential to ensure the validity of management recommendations. This study presents a mechanism to determine the optimal fishing strategy in the presence of parameter uncertainties using the Beverton and Holt yield per recruit model. The estimated population parameters of Amblygaster sirm (Clupeidae) off Western coastal waters of Sri Lanka by Karunasinghe ${ }^{6}$ 
Table 1: The parameter estimates made for $A$. sim from the western coastal waters of Sti Lanka."

\begin{tabular}{lc}
\hline Parameter & Value \\
\hline Asymptotic length $\left(\mathrm{L}_{\mathrm{o}}\right)$ & $25.4 \mathrm{~cm}$ \\
Growth constant $(\mathrm{K})$ & $0.98 \mathrm{year}^{-1}$ \\
Instantaneous rate of fishing mortality $(\mathrm{F})$ & $3.36 \mathrm{year}^{-1}$ \\
Instantaneous rate of natural mortality $(\mathrm{M})$ & 0.96 year ${ }^{-1}$ \\
Length at first capture $\left(\mathrm{L}_{\mathrm{c}}\right)$ & $14.95 \mathrm{~cm}$ \\
Length at recruitment $\left(\mathrm{L}_{\mathrm{r}}\right)$ & $10.5 \mathrm{~cm}$ \\
The maximum length of the fish in the stock $\left(\mathrm{L}_{\mathrm{p}}\right)$ & $23.5 \mathrm{~cm}$ \\
\hline
\end{tabular}

(Table 1) were used to demonstrate the proposed method. $A$. sirm is a small pelagic fish, found in the coastal waters of the Western Indian Ocean. ${ }^{7}$ It is highly abundant off the southern, western and the northwestern coastal waters of Sri Lanka and is frequently found in the catches of gillnets, purse seines and occasionally in beach seines operated at depths varying from 5-70 $\mathrm{m} .{ }^{8}$ The population parameters of $A$. sirm off the western coastal waters of Sri Lanka estimated by various authors showed substantial differences ${ }^{6,9,10}$

This paper also attempts to develop appropriate relationships between the uncertain parameters $\left(\mathrm{M}, \mathrm{W}_{\infty}\right.$ and $\mathrm{K}$ ) and optimal management parameters (maximum yield per recruit and optimum age at first capture).

\section{METHODS AND MATERIALS}

Theoretical age at length zero $\left(t_{\alpha}\right)$ was estimated using the empirical equation described by Pauly. ${ }^{11}$

$\log \left(-t_{0}\right)=-0.392-0.275 \log _{\infty}-1.038 \mathrm{~K}$

where $\mathrm{L}_{\infty}$ is asymptotic total length $(\mathrm{cm}) ; \mathrm{K}$ is on annual basis.

The following length-weight relationship ${ }^{6}$ was used to estimate $\mathrm{W}_{\infty}$ from $\mathrm{L}_{\infty}$.

$\mathrm{W}=0.01 \mathrm{~L}^{3}$

The length at first capture $\left(\mathrm{L}_{c}\right)$, length at recruitment $\left(\mathrm{L}_{\mathrm{r}}\right)$ and the maximum length of the fish in the stock $\left(\mathrm{L}_{\mathrm{r}}\right)$ were converted into corresponding ages $\left(t_{c}, t_{r}\right.$ and $\left.t_{p}\right)$ using the inverse von Bevtalanffy growth equation ${ }^{12}$,

$t=t_{0}-1 / K \ln \left(1-L_{t} / L_{\infty}\right)$

where $L_{t}=$ length at age $t$.
Table 2: Other estimated parameters of the Beverton and Holt yield per recruit model

\begin{tabular}{lc}
\hline Parameter & \multicolumn{1}{c}{ Value } \\
\hline Asymptotic weight $\left(\mathrm{W}_{\mathrm{o}}\right)$ & $163.87 \mathrm{~g}$ \\
Age at zeto length $\left(\mathrm{t}_{\alpha}\right)$ & -0.016 years \\
Age at first capture $\left(\mathrm{t}_{\mathrm{c}}\right)$ & 0.89 years \\
Age of recruitment $\left(\mathrm{t}_{\mathrm{r}}\right)$ & 0.53 years \\
Age of the oldest fish in stock $\left(\mathrm{t}_{\mathrm{p}}\right)$ & 2.63 years \\
\hline
\end{tabular}

The above estimates and the estimated values for other population parameters from the previous study (Table 1) were used as the initial inputs to the Beverton and Holt yield per recruit model; $\pm 10 \%$ variations from existing values of $\mathrm{M}, \mathrm{W}_{\infty}$ and $\mathrm{K}$ were assumed in the study. Thereby, 21 values were obtained for each of these parameters by making $1 \%$ variation at a time over the considered range. It should be noted that there are $9261(21 \times 21 \times 21)$ permutations for $M$, $\mathrm{W}_{\infty}$ and $\mathrm{K}$. For each combination of $\mathrm{M}, \mathrm{W}_{\infty}$ and $\mathrm{K}$, the maximum yield per recruit (Ypr max), age at first capture corresponding to the Ypr max (opt $t_{c}$ ) and the fishing mortality corresponding to the Ypr max $\left(\mathrm{F}_{\max }\right)$ were estimated by optimizing the Beverton and Holt yield per recruit function. In the optimization process, $\mathrm{F}$ and $\mathrm{t}_{\mathrm{c}}$ were allowed to vary over the acceptable ranges from 0.1 to 5 and 0.1 to 4 respectively. In terms of both parameters the step size was set at 0.01 . The other parameters of the Beverton and Holt yield per recruit model were fixed.

For estimation of optimal management parameter values over the above ranges of $F$ and $t_{c}$ for each combination of $M$, $\mathrm{W}_{\infty}$ and $\mathrm{K}$, a computer program in Pascal Language was used (available from author upon request). For each value of $M$, two types of contour plots were drawn using the Matlab computer software. In the first contour plot, maximum yield per recruit was plotted against $W_{\infty}$ and $\mathrm{K}$ In the second contour plot, opt $t_{c}$ was plotted against $W_{\infty}$ and $K$.

A multiple regression model was fitted to describe the relationship between the $Y$ pr max, $K, M$ and $W_{\infty}$ In this exercise, $\mathrm{Ypr}$ max was considered as the response variable while $\mathrm{M}, \mathrm{K}$ and $\mathrm{W}_{\infty}$ were considered as the predictor variables.

Ypr max $=B_{0}+B_{1} M+B_{2} W_{\infty}+B_{3} K+B_{4} K W_{\infty}+B_{5} K M$

$\beta_{6} \mathrm{MW}_{\infty}+\beta_{7} \mathrm{KMW}_{\infty}$

where $B_{0.7}$ are the parameters to be determined.

A multiple regression model was also fitted to predict the opt $t_{c}$. This multiple regression analysis was carried out using Microsoft Excel. In the process of 


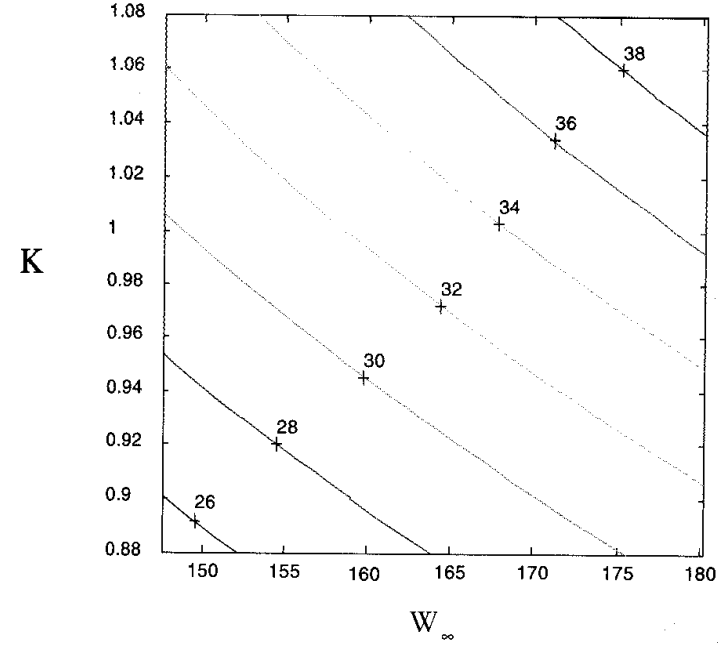

Figure 1: Maximum yield per recruit (Ypr max) contour as a function of asymptotic weight (W) and growth constant (K) at the Natural mortality (M) of 0.86 for $A$. sirm in the west coast of Sri Lanka.

deriving the regression models, the total number of parameter combinations (9261) was taken into consideration.

\section{RESULTS}

The estimated values for $\mathrm{W}_{\infty}, \mathrm{t}_{i,}, \mathrm{t}_{\mathrm{c},} \mathrm{t}_{\mathrm{r}}$ and $\mathrm{t}_{1}$ for $A$. sirm based on the values in Karunasinghe ${ }^{6}$ (Table 1) are given in Table 2. The estimated optimal yield per recruit based on the above study was $29.43 \mathrm{~g}$. The corresponding opt $\mathrm{t}_{\mathrm{c}}$ and $F_{\max }$ were 1.24 years and 5.0 year $^{-1}$ respectively.

The contour plots of Ypr max and opt $t_{c}$ against $W_{\infty}$ and $\mathrm{K}$ for $\mathrm{M}=0.86$ only are shown in Figure 1 and Figure 2 respectively. All other contour plots for different values of $M$ were similar in shape, but there were considerable differences between the two types of contour plots. Since the opt $t_{c}$ contours are parallel to the $W_{\infty}$ - axis, opt $t_{c}$ is independent of $W_{\infty}$.

The estimated minimum value for the Ypr max was $20.9 \mathrm{~g}$. The corresponding combination of percentage perturbation of $\mathrm{M}, \mathrm{W}_{\infty}$ and $\mathrm{K}$ was $10,-10$ and $-10 \%$ respectively. Similarly, the estimated maximum value for $\mathrm{Ypr}$ max was $40 \mathrm{~g}$ and the corresponding combination of percentage perturbation of $\mathrm{M}, \mathrm{W}_{\infty}$ and $\mathrm{K}$ was $-10,10$ and $10 \%$, respectively. Therefore, if the estimated values of $\mathrm{M}$, $\mathrm{W}_{\infty}$ and $\mathrm{K}$ varied by $\pm 10 \%$ the Ypr max would vary from 29 to $36 \%$ with respect to the initial prediction of Ypr max of the Beverton and Holt model.

The $\mathrm{F}_{\max }$ was almost the same $\left(5\right.$ year $\left.^{-1}\right)$ for all combinations. This implies that if the fishing mortality

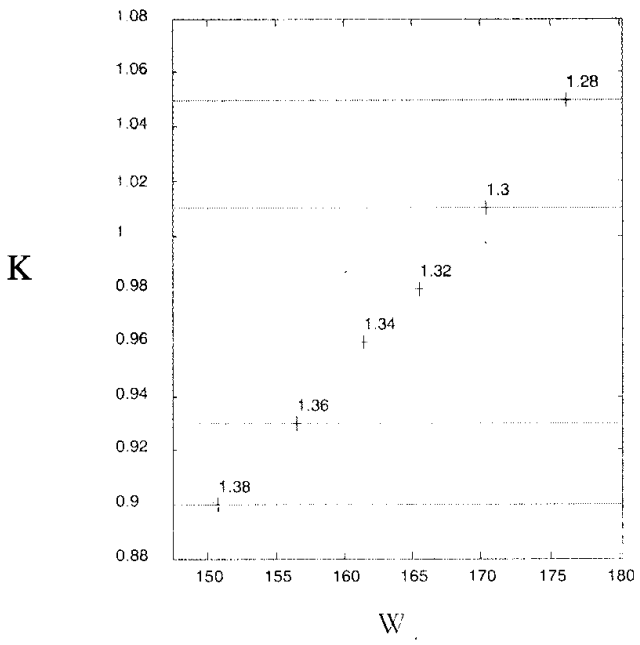

Figure 2: Optimal Age at the first capture (opt $\mathbf{t}$ ) contours as a function of asymptotic weight (W $)$ and growth constant $(\mathrm{K})$ at the natural mortality $(\mathrm{M})$ of 0.86 for $A$. sirm in the west coast of Sri Lanka.

varies from $0.1-5$ year $^{-1}$, the Ypr max is achieved only when the fishing mortality is equal to 5 year $^{-1}$. It should also be noted that for different combinations of $\mathrm{M}, \mathrm{W}_{\infty}$ and $\mathrm{K}$ the estimated values for opt $t_{c}$ were also different. As opt $t_{c}$ is independent of $\mathrm{W}_{\infty}$ the minimum value for opt $t_{c}$ could be obtained at the $10 \%$ variation of $M$ and $K$ which is 1.12 years. Similarly, the maximum value for opt $t_{c}$ could be obtained at $-10 \%$ perturbation of $\mathrm{M}$ and $\mathrm{K}$ (1.39 years). Therefore, the estimated range for the opt $t_{c}$ was $1.12-1.39$ years.

The analysis of variance indicated that the estimated coefficients of the terms $\mathrm{KW}_{\infty}, \mathrm{MW}_{\infty}$ and $\mathrm{KMW}_{\infty}\left(\beta_{4,} \beta_{6}\right.$ and $B_{7}$ respectively) were significant at the $99 \%$ probability level (Table 3 ). The best model to derive Ypr max $\left(\mathrm{R}^{2}=0.99\right.$, Table 4) was:

Ypr max $=0.343 \mathrm{KW}_{\infty}-0.055 \mathrm{MW}_{\infty}-0.104 \mathrm{KMW}_{\infty}$

It was noted that opt $t_{c}$ depends upon $K$ and $M$ only. Therefore, a multiple regression model was fitted between opt $\mathrm{t}_{\mathrm{c}}, \mathrm{M}$ and $\mathrm{K}$ :

opt $t_{c}=\alpha_{0}+\alpha_{1} M+\alpha_{2} K+\alpha_{3} M K$

where $\alpha_{0-3}$ are the parameters to be determined. The statistical analysis indicated that all the coefficients were significant at the $99 \%$ probability level (Table 5).

The best model to derive opt $\mathrm{t}_{\mathrm{c}}\left(\mathrm{R}^{2}=0.99\right.$ : Table 6) was:

opt $t_{c}=3.048-1.2266 \mathrm{M}-1.108 \mathrm{~K}+0.4896 \mathrm{MK}$ 
Table 3: Parameter estimates of the regression model of maximum yield per recruit (Ypr max)

\begin{tabular}{lccl}
\hline Parameter & Value & Standard Error & $\mathrm{P}-$ value \\
\hline$B_{0}($ Constant $)$ & 0.092 & 3.1807 & 0.98 \\
$B_{3}(\mathrm{M})$ & -0.115 & 3.3067 & 0.97 \\
$B_{2}\left(\mathrm{~W}_{\infty}\right)$ & -0.007 & 0.0193 & 0.72 \\
$B_{3}(\mathrm{~K})$ & -0.095 & 3.2395 & 0.98 \\
$\left.B_{4}(\mathrm{KW})_{\infty}\right)$ & 0.343 & 0.0197 & $5.45 \mathrm{E}-67$ \\
$B_{5}(\mathrm{KM})$ & 0.120 & 3.3677 & 0.97 \\
$\left.B_{6}(\mathrm{MW})_{\infty}\right)$ & -0.055 & 0.0201 & 0.006 \\
$B_{7}\left(\mathrm{KMW}_{\infty}\right)$ & -0.104 & 0.0205 & $4.58 \mathrm{E}-07$ \\
\hline
\end{tabular}

Table 4: Analysis of variance of the tegression model of maximum yield per recruit ( $\mathrm{Ppr}$ max)

\begin{tabular}{lrcccc}
\hline & df & SS & MS & F & Significance F \\
\hline Regression & 7 & 106773.2 & 15253.31 & 2956574 & 0 \\
Residual & 9253 & 47.73732 & 0.005159 & & \\
Total & 9260 & 106820.9 & & & \\
\hline
\end{tabular}

\section{DISCUSSION}

Quantifying the uncertainties in fisheries stock assessment is essential to ensure the validity of management recommendations for sustainable use of fisheries resources. The present exercise attempted to describe the influence of parameter uncertainties on fishery resources evaluation to bring about optimal fishing strategies, using an example of available information on $A$. sirm fishery off the western coastal waters of Sri Lanka.

There is a substantial difference between the estimated population parameters ( $\mathrm{L}_{\infty}, \mathrm{K}$ and $\mathrm{M}$ ) of $A$. sirm from the western coastal waters of Sri Lanka between 1980-1990. The estimated values for $L_{\infty}$ and $K$ varied from $22.9-26.0 \mathrm{~cm}$ and $0.95-2.38$ year $^{-1}$ respectively. ${ }^{6,9,10}$ In addition, the estimated values for $\mathrm{M}$ varied from $0.96-2.12$ year $^{-1}$. The uncertainty on optimal fishing strategy greatly depends on $\mathrm{L}_{\infty}, \mathrm{K}$ and $\mathrm{M}$, while the other parameters such as $t_{1}$ have little influence on the output. It should also be noted that the two models derived for optimal fishing strategies (i.e. two regression models derived to predict Ypr max and opt $t_{c}$ ) were based on input values of all parameters of the Beverton and Holt yield per recruit model. However, the best models of optimal fishing strategies (see results) consist of at most three parameters of $\mathrm{W}_{\infty}$, $\mathrm{M}$ and $\mathrm{K}$. Therefore, estimation of $\mathrm{Ypr} \max$ and opt $\mathrm{t}_{\mathrm{c}}$
Table 5: Parameter estimates of the regression model of optimal age at first capture (opt $\mathbf{t}_{\mathrm{c}}$ )

\begin{tabular}{lccl}
\hline Parameter & Value & Standard Error & $P$ - value \\
\hline$\alpha_{0}$ (Constant) & 3.048 & 0.0091 & 0.005 \\
$\alpha_{1}(\mathrm{M})$ & -1.2266 & 0.0094 & $4.5 \mathrm{E}-25$ \\
$\alpha_{2}(\mathrm{~K})$ & -1.108 & 0.0092 & 0.001 \\
$\alpha_{3}(\mathrm{MK})$ & 0.4896 & 0.0097 & 0.003 \\
\hline
\end{tabular}

Table 6: Analysis of variance of the regression model of optima age at first capture (opt $t_{c}$ )

\begin{tabular}{lrrrrr}
\hline & df & \multicolumn{1}{c}{ SS } & MS & F & Significance F \\
\hline Regression & 3 & 32.77033 & 10.92344 & 940090.5 & 0 \\
Residual & 9257 & 0.107562 & $1.16 \mathrm{E}-05$ & & \\
Total & 9260 & 32.8779 & & & \\
\hline
\end{tabular}

using these multiple regression models is much easier compared to the use of the full Beverton and Holt yield per recruit model as the information requirement is relatively low. Hence the initial cost of collecting fisheries data would also be lower.

The present work was conducted to evaluate the effects of parameter uncertainties and the sensitivity of the input parameters of the Beverton and Holt yield per recruit model on determination of the optimal fishing strategy for the $A$. sirm fishery in the western coastal waters of Sri Lanka. Therefore, these models are not directly applicable to any other species. However, there is a possibility of adopting a similar procedure for estimation of appropriate models for different species.

\section{Acknowledgement}

I thank Professor U.S. Amarasinghe of the University of Kelaniya, for introducing me to the subject and stimulating discussions on the topic. I am grateful to Dr W.B. Daundasekera, University of Peradeniya, Dr S.K. Boralugoda, Dr. M. Liyanage and Mr P. Dias of the University of Sri Jayewardenepura and Dr. P.A.A.T Jayawardane of the National Aquatic Resources Research and Development Agency for their valuable support, guidance and encouragement to complete this study successfully.

\section{References}

1. Thompson W.F. \& Bell F.H. (1934). Biological statistics of the Pacific halibat fishery 2. Effects of change in intensityupon total yield per unit of gear. Report of the International Fsisbery (Pacific Halibut) Commission p. 8, 49. 
2. Schaefer M.B. (1954). Some aspects of the dynamics of populations important to management of commercial marine fisheries. Bulletin of the Inter-American Tropical Tuna Commisrion 1: $25-56$

3. Beverton R.\}.H. \& Holt S.J. (1957). On the dynamics of exploited fish populations. Fisheries Investigations (Ser. 2) 19. p. 533. U.K. Ministry of Agriculture Fisheries.

4. Pitcher T.J. \& Hart P.J.B. (1982). Fisheries Ecology. p. 414 Croom Helm, London.

5. Sparre P. \& Venema S.C. (1998). Introduction to tropical fish stock assessment. Part 1 Manual. FAO Fisheries Tecbnical Paper. No. 306. p. 407. Food and Agriculture Organization, 1, Rev. 2. Rome.

6. Karunasinghe W.P.N. (1990). Some aspects of biology \& fishery of trenched Sardine Amblygaster sirm (Pisces: Clupeidae) from the coastal waters around Negombo, Sri Lanka. M. Phil. Thesis, University of Kelaniya, Kelaniya.

7. Frischer W. \& Bianchi G. (1984). FAO species identification sheets for fishery purposes. Western Indian Ocean (Fishing area
51). Prepared and printed with the support of the Danish International Development Agency (DANDA). Rome, FAO.

8. Karunasinghe W.P.N \& Wijeyaratne M.J.S. (1995). Studies on the exploitation of trenched Sardine Amblyngarter sirm (Walbaum) off the Negombo coast. Journal of the National Science Council of Sri Lanka 23: 1-7.

9. Dayaratne P. (1984). Fishery and biology of some small pelagic fish species (Clupeioides) from the West Coast Sri Lanka. Ph. D. Thesis, University of Bergen, Norway.

10. Siddeek M.S.M., Joseph L., Jayasuriya P.M.A. \& Karunasinghe W.P.N. (1985). A preliminary analysis of length frequency data of Amblygaster sirm from Negombo, Sri Lanka, using ELEFAN programs. Journal of the National Aquatic Resources Agency of Sri Lanka 32: 35 - 46.

11. Pauly D. (1979). Theory and management of tropical multiskecies stocks: A review with emphasis on the Soutbeast Asian Demersal Fisheries. ICLARM Studies and Reviews. p.35

12. Gulland J.A. (Ed.) (1977). Fish population dynamics. Wiley Interscience, New York. p.372 